\title{
A Rare Case of Desmoid Tumor of Thigh
}

\author{
Anupam Tiwari • Margaret Topno • Tanweer Karim • \\ Vinod Sharma
}

Received: 27 October 2008 / Accepted: 2 December 2008/Published online: 23 November 2010

(C) Association of Surgeons of India 2010

\begin{abstract}
Extraabdominal desmoid tumor is a locally aggressive tumor despite being histologically benign. To avoid local recurrence, it is important to preoperatively detect the exact localization and extension of the infiltrating or disseminating lesion in this tumor. We report a case of recurrent extraabdominal desmoid tumor, which arose in the posterior thigh region. A 68 yrs old male presented with thigh swelling since past 22 years over posterior aspect of thigh increasing in size over the past 2 years. The swelling was extending over the medial and anterior aspect of thigh. On investigation he was found to be case of desmoid tumor of thigh.
\end{abstract}

Keywords Extra abdominal desmoid · Thigh swelling · Surgical excision

\section{Introduction}

Despite their benign histologic appearance and negligible metastatic potential, the tendency of desmoid tumors to cause local infiltration is significant in terms of [1] deformity, morbidity, and mortality resulting from pressure effects and [2] potential obstruction of vital structures and organs. Although desmoid tumors most commonly arise from the rectus abdominis muscle in postpartum period and in scars due to abdominal surgery. They may arise in any skeletal muscle. The tumors tend to infiltrate adjacent muscle bundles, frequently entrapping them and causing

A. Tiwari $(\bowtie) \cdot$ M. Topno $\cdot$ T. Karim $\cdot$ V. Sharma MGMMC,

Navi Mumbai, India

e-mail: dr_anupamt@yahoo.co.in their degeneration. Desmoid tumors are reported to account for $0.03 \%$ of all neoplasms [3]. Peripheral desmoid tumors are firm, smooth, and mobile.They often adhere to surrounding structures. The overlying skin is usually unaffected. The presence of such a soft tissue growth should alert the clinician to delve more deeply into the

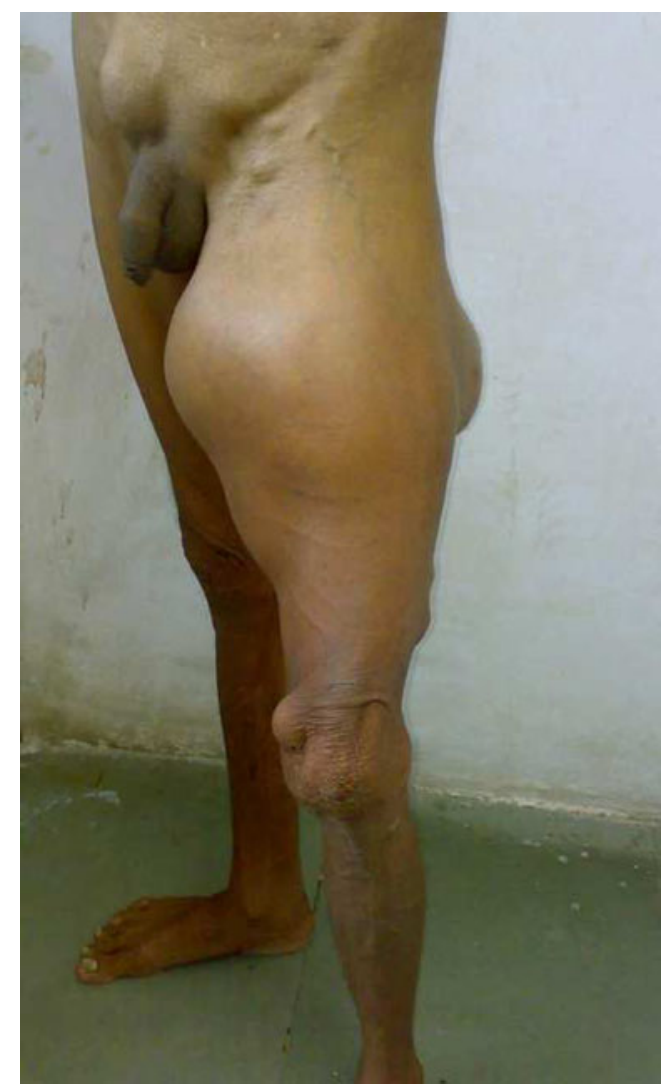

Photo 1 Desmoid tumor ant view 
family history for evidence of familial polyposis coli and Gardner syndrome [4, 5]. Extra-abdominal desmoid tumors are rare and may be first evident as gradually increasing leg swelling [6]. A 68 yr old male presented with desmoids tumor of left thigh. A brief overview of management is included Photos 1, 2, 3, 4 and 5.

Case Report A 68 yrs old male presented with swelling over left thigh since past 22 yrs increasing since last 2 yrs. He was operated for same swelling 8 times previously at various setups, when biopsies were done. This time he presented with tremendous increase in size and experienced difficulty while walking.

On examination swelling was present over middle third and lower third extending upto medial and anterior aspect of thigh of approx size $28 \times 22 \mathrm{~cm} 2$. The surface was

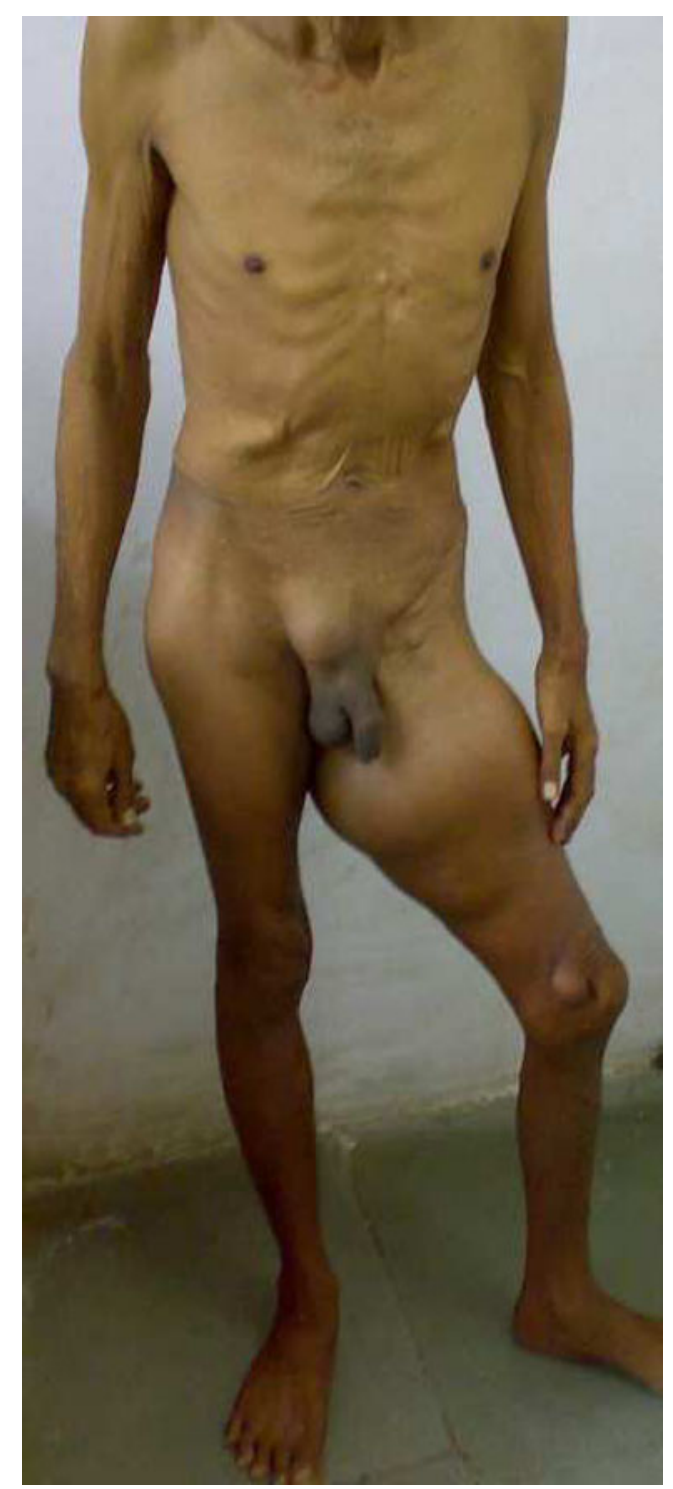

Photo 2 Post view

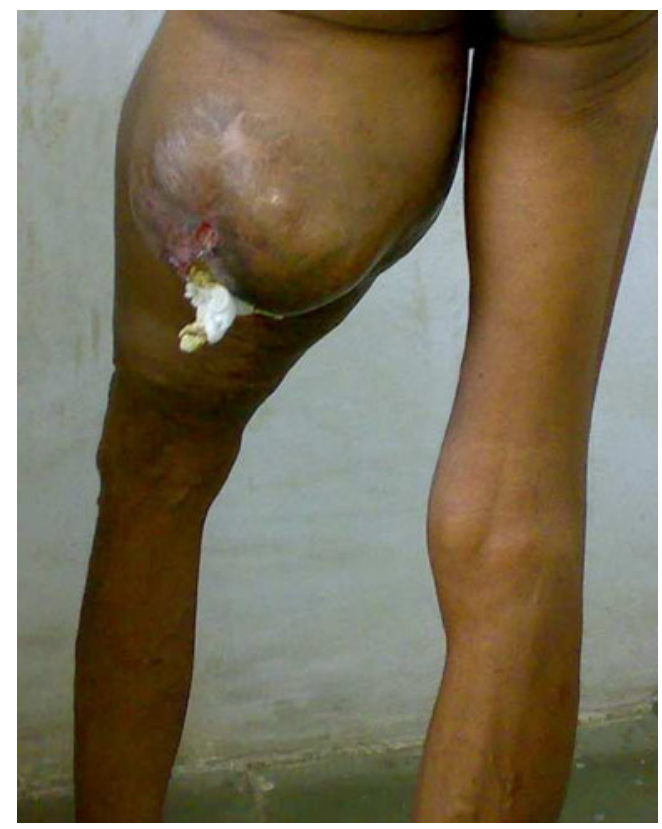

Photo 3 Ant view

bosselated .The skin was shiny with visible dilated veins. Hip and knee joint movements were restricted. Peripheral pulsations were well felt. On FNAC examination spindle cell myofibroblast were seen. On MRI, tumor appeared as masses of intensity equal to that of skeletal muscle on T1weighted images [7]. On T2-weighted images, tumor showed variable signal intensity relative to muscle.

Surgical wide excision was done $[8,9]$. Lazy ' $S$ ' incision was taken over anterior aspect of thigh. Femoral vessels and nerve were found engulfed by the tumor. Tumor was excised enbloc after advancing towards medial \& posterior

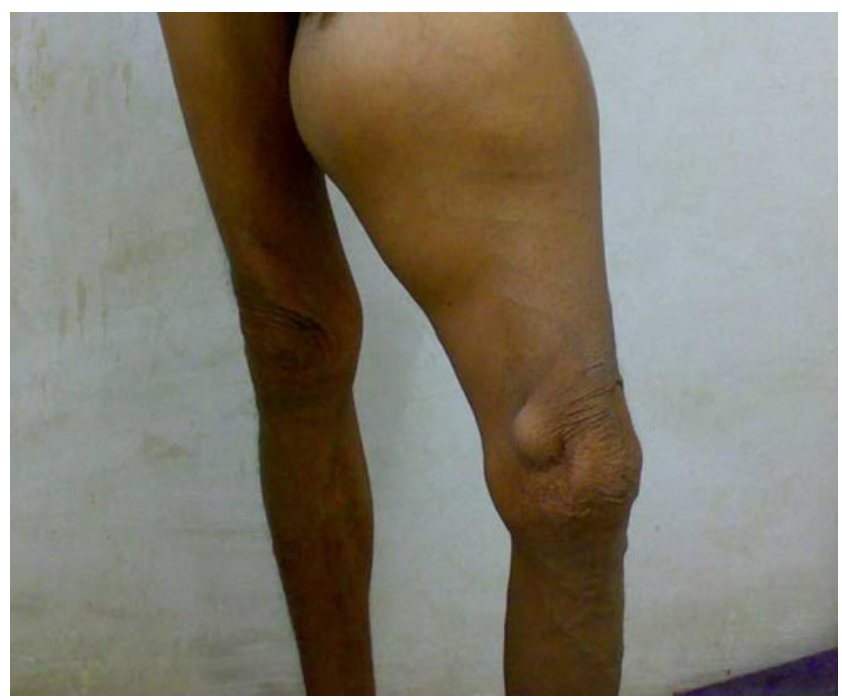

Photo 4 Medial view 


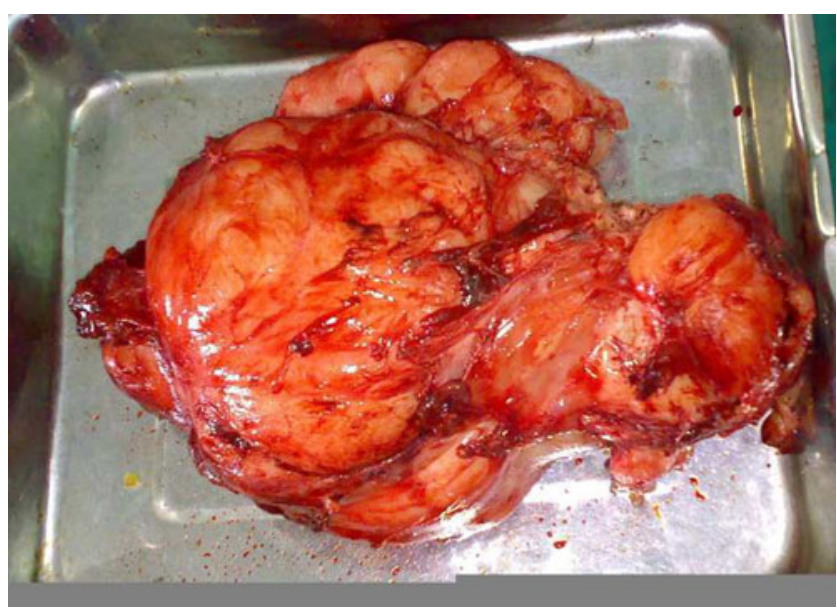

Photo 5 Specimen of excised tumor

compartment of thigh. Post operative recovery was uneventful. Patient was given active physiotherapy in the post operative period. The histology of the tumour was distinctive and consistently showed features of desmoids with margins free of tumor [10].

Discussion A case of extra-abdominal fibromatosis, is a rare entity, For potentially resectable lesions, surgery provides excellent local control, even in those with recurrent disease [10].

\section{References}

1. Brueckl WM, Ballhausen WG, Förtsch T, Günther K, Fiedler W, Gentner B et al (2005) Genetic testing for germline mutations of the APC gene in patients with apparently sporadic desmoid tumors but a family history of colorectal carcinoma. Dis Colon Rectum 48(6):1275-1281

2. Sturt NJ, Gallagher MC, Bassett P, Philp CR, Neale KF, Tomlinson IP et al (2004) Evidence for genetic predisposition to desmoid tumours in familial adenomatous polyposis independent of the germline APC mutation. Gut 53(12):1832-1836

3. Shields CJ, Winter DC, Kirwan WO, Redmond HP (2001) Desmoid tumours. Eur J Surg Oncol 27(8):701-706

4. Gurbuz AK, Giardiello FM, Petersen GM, Krush AJ, Offerhaus GJ, Booker SV et al (1994) Desmoid tumours in familial adenomatous polyposis. Gut 35(3):377-381

5. Klemmer S, Pascoe L, DeCosse J (1987) Occurrence of desmoids in patients with familial adenomatous polyposis of the colon. Am J Med Genet 28(2):385-392

6. Agrawal PS, Jagtap SM, Mitra SR (2008) Extra-abdominal desmoid tumour of the leg. Singapore Med J 49(1):e6-e7

7. Bernard J (2002) Value of MRI to evaluate extra-abdominal desmoid fibromatosis. J Radiol 83(6 Pt 1):711-716

8. Stout AP (1954) Juvenile fibromatosis. Cancer 7:953-971, $r$. Sep 1 2005;104(5):1090-1099

9. Pritchard DJ, Nascimento AG, Peterson IA (1996) Local control of extra-abdominal desmoid tumours. J Bone Joint Surg Am 78:848-854

10. Buitendijk S, van de Ven CP, Dumans TG, den Hollander JC, Nowak PJ, Tissing WJ et al (2005) Pediatric aggressive fibromatosis: a retrospective analysis of 13 patients and review of literature. Cancer 104(5):1090-1099 